\title{
Improved immobilization of 8-hydroxyquinoline on polyacrylonitrile fiber and application of the material to the determination of trace metals in seawater by inductively coupled plasma mass spectrometry
}

Received: 20 May 2002 / Revised: 19 July 2002 / Accepted: 29 July 2002 / Published online: 8 October 2002

(C) Springer-Verlag 2002

\begin{abstract}
A modified synthetic method has been developed for immobilization of 8-hydroxyquinoline on polyacrylonitrile fiber. The synthetic conditions, e.g. reagent concentration, reaction temperature and time, were optimized. The features of the newly-modified fiber are higher exchange capacity compared with most other materials containing immobilized 8-hydroxyquinoline, better mechanic characteristics, high stability at both high and low $\mathrm{pH}$, and ease of synthesis. This modified fiber can concentrate and separate trace metals from matrices with higher concentrations of alkali and alkaline earth elements. To validate the characteristics of the modified fiber, trace metals $\mathrm{Ag}, \mathrm{Be}, \mathrm{Cd}, \mathrm{Co}, \mathrm{Cu}, \mathrm{Mn}, \mathrm{Ni}, \mathrm{Pb}$, and $\mathrm{Zn}$ in the certified reference materials river water (SLRS-4) and seawater (CASS-4, NASS-5, SLEW-3) were preconcentrated before determination by inductively coupled plasma mass spectrometry. Good agreement was obtained between the data obtained by this method and the certified values.
\end{abstract}

Keywords 8-Hydroxyquinoline immobilized polyacrylonitrile fiber - Trace metals - Sea water . Inductively coupled plasma mass spectrometry

\section{Introduction}

Inductively coupled plasma mass spectrometry (ICP-MS) is one of the most accurate, sensitive, and reliable techniques for the determination of trace metals and has been widely used for determination of trace elements in environmental samples. Its low tolerance of dissolved solids $(<0.1 \%, w / v)$, however, prohibits the direct analysis of trace elements in seawater by ICP-MS, because of the

B. Wen · X.-q. Shan (文)

Research Center for Eco-Environmental Sciences,

Chinese Academy of Sciences,

P.O. Box 2871, Beijing 100085, China

e-mail: xiaoquan@mail.rcees.ac.cn problem of salt deposition on the torch, sampling interface, or ion lenses. In ICP-MS interferences fall broadly into two groups, "spectroscopic", and "non-spectroscopic" or "matrix effects". The extent of the interferences depends on many factors including extraction geometry, plasma and nebulizer system operating conditions, and, most importantly, on the nature of the analytes and matrix. To minimize interferences many approaches have been recommended, including instrument optimization, use of mixed gases and/or "dry" sample introduction, sample dilution, sample-matrix matching, and use of internal standards, etc. [1]. It should be pointed out that these interferences are usually related to the nature of the sample matrix and much can be done to minimize or even eliminate potential problems by careful sample preparation. It must be admitted that for simultaneous multi-element determination by ICP-MS in a complex matrix such as seawater separation and/or pre-concentration methods are the first choice $[1,2,3]$.

8-Hydroxyquinoline is a well-characterized chelating organic ligand. It can form covalent compounds with over 60 metal ions under controlled $\mathrm{pH}$ conditions, and its preference for transition and heavy metals to alkali and alkaline-earth elements is well known [4]. Trace elements are usually chelated with solution of 8-hydroxyquinoline and then extracted with organic solvent [5]. In comparison with the most commonly used solvent extraction enrichment procedures, however, column solid-phase extraction enables preconcentration of trace elements from larger volumes of sample, and so higher concentration factors, simple storage and easy transport of the pretreated samples can be achieved $[6,7,8]$.

Much research has recently been performed to establish the most effective means of immobilization of 8-hydroxyquinoline on a number of suitable substances, including glass beads [9], silica gel [10, 11], polystyrenedivinylbenzene [12], and vinyl polymer agglomerate [13], and the characteristics of the different products have been compared [14]. 8-Hydroxyquinoline immobilized on silica gel is one of the most frequently used ion exchangers and is commercially available $[14,15,16]$. It is, however, 
unstable at high $\mathrm{pH}$, leading to cleavage of the immobilized 8-hydroxyquinoline and potential trace metal contamination from the newly exposed silica surface $[17,18]$.

Fibers such as polyethylene, polypropylene, cellulose, and polyacrylonitrile, are good supports. They have high specific surface areas, approximately two orders of magnitude larger than that of a gel-structure granular ion-exchanger or 5-6 times that of a porous copolymer. The particle diameter of a fibrous ion exchanger is 1-2 orders of magnitude less than the mean diameter of a granular material. Fibers also differ from crosslinked granular polymers in the presence of linear or branched macromolecules, which might have swelling capacity [18]. Thus fibrous ion-exchangers have good kinetic and mechanical characteristics.

In our previous work, poly(acrylaminophosphonic dithiocarbamate) chelating fiber was developed and used to preconcentrate trace elements from seawater $[2,19]$. The synthesis was, however, time-consuming - approximately four days. 8-Hydroxyquinoline has also been immobilized onto a polyacrylonitrile hollow fiber membrane [20, 21]. Because of the low mechanical strength of the membrane, however, it is easily damaged during the synthesis and the reaction conditions, e.g. reaction temperature and time, are limited leading to low yield and exchange capacity. These drawbacks also restrict its widespread application in analytical chemistry.

The aim of this study was to improve the synthetic route to immobilization of 8-hydroxyquinoline onto polyacrylonitrile fiber, to overcome the above-mentioned drawbacks of previous synthetic procedures. The conditions used in the newly recommended synthetic procedure, e.g. reagent concentration, reaction temperature and time etc., were optimized. The distinct features of the modified fiber include ease of synthesis, higher breakthrough capacity, better mechanical characteristics, and stability under highly acidic and alkaline conditions. The modified fiber has been applied to the preconcentration of trace elements in certified seawater and river water reference materials before determination by ICP-MS and good agreement was achieved between the data obtained by this method and the certified values.

\section{Experimental}

Reagents and solutions

Stock solutions of each trace metal for sample analysis, $1000 \mathrm{mg} \mathrm{L}^{-1}$, were prepared by dissolving appropriate amount of metal oxide (Specpure, Johnson Matthey Chemicals) in nitric acid $(67 \%, 5 \mathrm{~mL})$. Single and multi-element standard solutions of concentration 10,50, and $100 \mathrm{ng} \mathrm{mL}^{-1}$ were prepared from the stock solutions by serial dilution with dilute $\mathrm{HNO}_{3}$. The final acid concentration of all standard solutions was fixed at $0.1 \mathrm{~mol} \mathrm{~L}-1 \mathrm{HNO}_{3}$.

All other reagents were of analytical grade or better. High purity water $(18 \mathrm{MO} \mathrm{cm})$ was used. Nitric acid was purified by subboiling distillation in a quartz still using ultrapure grade $\mathrm{HNO}_{3}$ as feed. All other acids used were of ultrapure grade (Beijing Chemicals, China).

Polyacrylonitrile fiber was obtained from Shuangyang Chemical Factory (Beijing, China) and rinsed before use.

Before use all beakers, funnels, calibrated flasks, and other glassware were soaked in nitric acid $(1+1)$ for $48 \mathrm{~h}$.

Certified seawater CASS-4, NASS-5, SLEW-3 and river water SLRS-4 samples were purchased from the Institute for National Measurement Standards, National Research Council, Canada.

Instrumentation

A Plasma-Quad 3 (VG Elemental, Winsford, UK) inductively coupled plasma-mass spectrometer (ICP-MS) was used for determination of trace elements in water. The optimum instrumental conditions are given in Table 1. Indium was added as internal standard to monitor matrix effects and signal drift.

Immobilization procedure

Step 1

Rinsed fiber $(10 \mathrm{~g})$ and hydrazine hydrate $(30 \%, \mathrm{v} / \mathrm{v} ; 400 \mathrm{~mL})$ were mixed in a 1-L flat-flange reaction vessel and reacted for $4 \mathrm{~h}$ at $94-96^{\circ} \mathrm{C}$ in water bath. The hydrazine-modified fiber was isolated by filtration and washed with double-distilled deionized water. After washing, the fiber was dried and weighed.

Step 2

The hydrazine-modified fiber was further aminated by reaction with diethylenetriamine $(50 \% \mathrm{v} / \mathrm{v} ; 400 \mathrm{~mL})$ for $6 \mathrm{~h}$ at $95^{\circ} \mathrm{C}$ in water-bath, suction-filtered, and washed with ethanol $(99.5 \%)$ and then with double-distilled deionized water until the $\mathrm{pH}$ was neutral. Then the fiber was dried and weighed.

Table 1 ICP-MS operating conditions

ICP

Forward power

Reflected power

Coolant argon flow rate

Auxiliary argon flow rate

Nebulizer argon flow rate

Sample uptake rate

Sampling depth

Mass spectrometry

Sampler (nickel) orifice

Skimmer (nickel) orifice

3rd stage pressure

Data acquisition

Total acquisition time

Replication integrations per sample run

Element

$\mathrm{Ag}$

$\mathrm{Be}$

$\mathrm{Cd}$

Co

$\mathrm{Cr}$

$\mathrm{Cu}$

$\mathrm{Ni}$

$\mathrm{Mn}$

$\mathrm{Pb}$

$\mathrm{Zn}$

$1350 \mathrm{~W}$
$<5 \mathrm{~W}$
$14 \mathrm{~L} \mathrm{~min}^{-1}$
$0.9 \mathrm{~L} \mathrm{~min}^{-1}$
$0.8 \mathrm{~L}$
$1.0 \mathrm{~mL} \mathrm{~min}-1$
$15 \mathrm{~mm}$

$1.0 \mathrm{~mm}$
$0.7 \mathrm{~mm}$
$1.7 \times 10^{-1} \mathrm{mPa}$
Range-scanning mode
$60 \mathrm{~s}$
3
Mass
107
9
114
59
52
65
60
55
208
66


Step 3

The diethylenetriamine-modified fiber was soaked in $400 \mathrm{~mL}$ of a solution of $20 \mathrm{~g} \mathrm{NaNO}_{2}$ in $0.2 \mathrm{~mol} \mathrm{~L}^{-1}$ acetic acid for $1 \mathrm{~h}$ at $0^{\circ} \mathrm{C}$. The product was filtered and rinsed with ice-cold double-distilled deionized water and then added to a $200 \mathrm{~mL}$ solution of $4 \mathrm{~g}$ of 8 -hydroxyquinoline in $95 \% \mathrm{EtOH}$. After reaction for $1 \mathrm{~h}$ the diazocoupled 8-hydroxyquinoline product was isolated by filtration and rinsed sequentially with $500 \mathrm{~mL} 0.5 \mathrm{~mol} \mathrm{~L}^{-1} \mathrm{NaOH}, 500 \mathrm{~mL} \mathrm{H}_{2} \mathrm{O}$, $500 \mathrm{~mL} 1.0 \mathrm{~mol} \mathrm{~L}^{-1} \mathrm{HCl}$, and three portions of $500 \mathrm{~mL}$ double-distilled deionized water. After rinsing the 8-hydroxyquinoline-modified fiber was dried and weighed.

Packing of 8-hydroxyquinoline-modified polyacrylonitrile fiber columns

Glass columns ( $4 \mathrm{~mm}$ i.d., $50 \mathrm{~mm}$ height) were plugged at the bottom with small amounts of glass-wool treated with $1 \% \mathrm{HNO}_{3}$. After thorough draining and rinsing with doubly-distilled deionized water $100 \mathrm{mg}$ fiber, cut into lengths of approximately $1 \mathrm{~mm}$ and suspended in water, was slurry-packed into the columns which were then plugged with small amounts of glass wool inserted on the top of the fiber bed. The columns were rinsed first with $100 \mathrm{~mL}$ distilled water, then with $20 \mathrm{~mL} 2 \mathrm{~mol} \mathrm{~L}^{-1} \mathrm{HCl}-0.1 \mathrm{~mol} \mathrm{~L}^{-1} \mathrm{HNO}_{3}$, and finally with doubly deionized distilled water until the $\mathrm{pH}$ of the eluate was neutral.

Fiber batch capacity

The chelating capacity of the 8-hydroxyquinoline-modified fiber was determined for each metal ion by a batch technique. Fiber $(\sim 50 \mathrm{mg})$ was equilibrated with each metal ion by shaking for $24 \mathrm{~h}$ at $\mathrm{pH} 6$ in excess metal ion solution $\left(50 \mathrm{~mL}, 50 \mu \mathrm{g} \mathrm{mL}^{-1}\right)$. The modified fiber was then separated from the solution by filtration and the concentration of the metal ions remaining in the solution was determined by ICP-MS.

\section{Breakthrough study}

Breakthrough studies were also chosen for characterization of the modified fiber, because they are more illustrative of dynamic column operation. Breakthrough curves were determined at different column flow rates using $1 \mu \mathrm{g} \mathrm{mL}^{-1} \mathrm{Cu}(\mathrm{II})$ at the desired $\mathrm{pH}$, adjusted by addition of high-purity aqueous ammonia or nitric acid. Eluate fractions were collected every $3 \mathrm{~min}$ by use of a fraction collector. The amounts of $\mathrm{Cu}$ (II) in each portion of eluate were determined by ICP-MS

Preconcentration of trace elements from seawater and river water samples

Water samples $(500 \mathrm{~mL})$ were adjusted to $\mathrm{pH} 6$, adjusted by addition of high-purity aqueous ammonia or nitric acid, then applied to the modified fiber column, at a flow rate of $5 \mathrm{~mL} \mathrm{~min}$, by use of a peristaltic pump. After washing with $50 \mathrm{~mL}$ doubly distilled deionized water, the trace elements retained in the column were eluted with $5 \mathrm{~mL} 2 \mathrm{~mol} \mathrm{~L}^{-1} \mathrm{HCl}-0.1 \mathrm{~mol} \mathrm{~L}^{-1} \mathrm{HNO}_{3}$ at a flow rate of $1 \mathrm{~mL} \mathrm{~min}-1$.

\section{Results and discussion}

Optimum synthetic conditions

To immobilize as much 8-hydroxyquinoline as possible on the polyacrylonitrile fiber the synthetic conditions, e.g. reagent concentration, reaction temperature, and time,

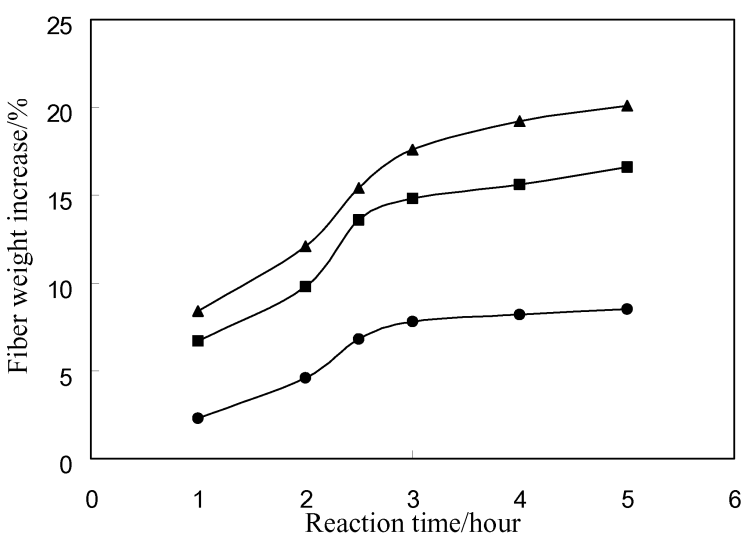

Fig. 1 Effect of reaction time, temperature, and concentration of hydrazine hydrate on the increase in the weight of the fiber (circles, $30 \%$ hydrazine hydrate, $90-92^{\circ} \mathrm{C}$; squares, $30 \%$ hydrazine hydrate, $94-96^{\circ} \mathrm{C}$; triangles, $40 \%$ hydrazine hydrate, $94-96^{\circ} \mathrm{C}$ )

were optimized. The relative fiber weight increase was used as an indicator.

As shown in Fig. 1, the weight of the fiber increased sharply when the time of reaction with hydrazine hydrate was increased from 1 to $3 \mathrm{~h}$, and then remained unchanged when the reaction time was further increased. Increasing the reaction temperature from $90-92^{\circ} \mathrm{C}$ to $94-96{ }^{\circ} \mathrm{C}$ significantly improved the reaction efficiency. Increasing the concentration of hydrazine hydrate from $30 \%$ to $40 \%$ (v/v) led to a $5 \%$ increase in the mass of the fiber after reaction for $4 \mathrm{~h}$. The best synthetic results were obtained with an initial hydrazine hydrate concentration of $40 \%(\mathrm{v} / \mathrm{v})$ in the temperature range $94-96^{\circ} \mathrm{C}$. Because these reaction conditions are very close to the lower limits for the explosion of hydrazine hydrate gas mixtures, however [18], the concentration of hydrazine hydrate was limited to $30 \%(\mathrm{v} / \mathrm{v})$. At the end of this procedure, the color of the white fiber turned to pale yellow.

Figure 2 reveals that the reaction between the hydrazine-modified fiber and diethylenetriamine depends

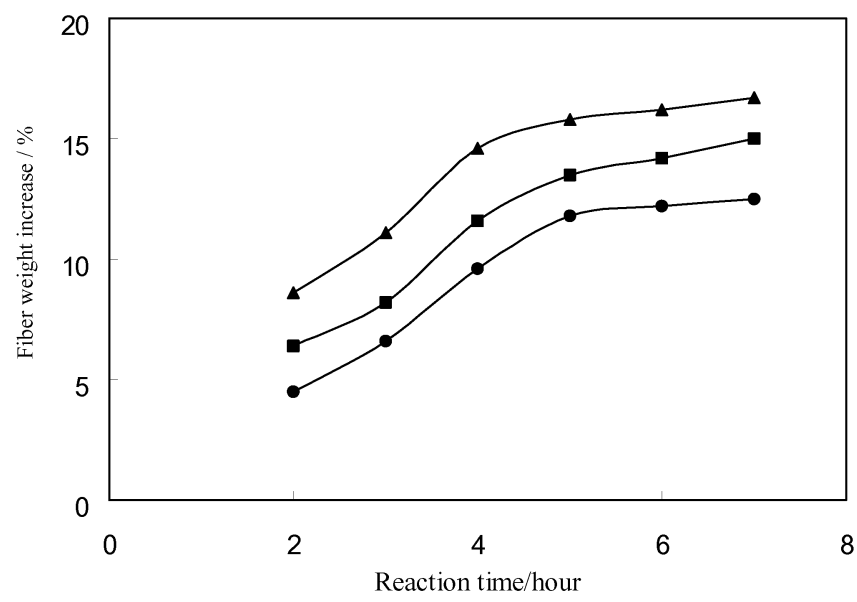

Fig. 2 Effect of reaction time, temperature, and concentration of diethylenetriamine on the increase in the weight of the fiber (circles, $30 \%$ diethylenetriamine, $90{ }^{\circ} \mathrm{C}$; squares, $50 \%$ diethylenetriamine, $90^{\circ} \mathrm{C}$; triangles, $50 \%$ diethylenetriamine, $95^{\circ} \mathrm{C}$ ) 


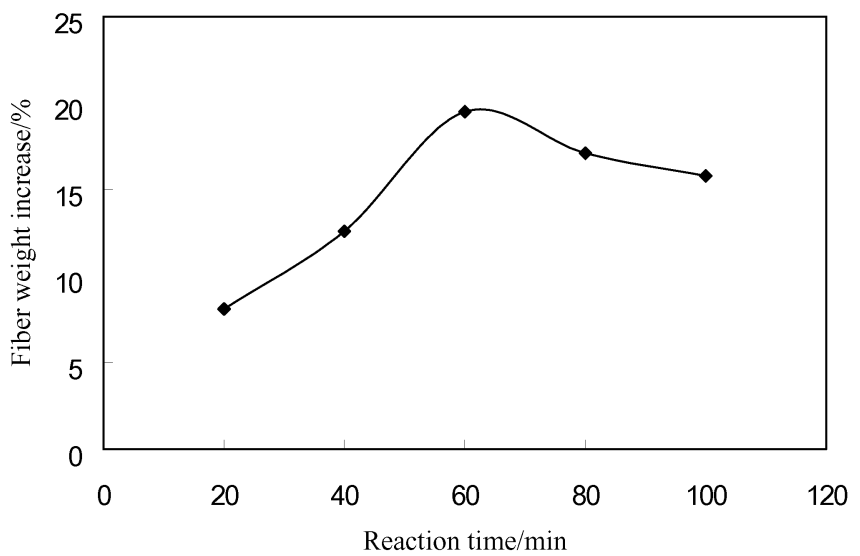

Fig. 3 Effect of reaction time between fiber and $\mathrm{NaNO}_{2}$ on the increase in the weight of the fiber

strongly on reaction temperature, time, and the concentration of diethylenetriamine. Increasing these resulted in a large increase in the weight of the fiber. For rapid synthesis $50 \%(\mathrm{v} / \mathrm{v})$ diethylenetriamine and $95^{\circ} \mathrm{C}$ reaction temperature were chosen, and the reaction time was fixed at $6 \mathrm{~h}$, after which the increase in the weight of the hydrazine-modified fiber was $13.8 \%$, and the color of the fiber was red-orange.

As shown in Fig. 3, when the reaction time with $\mathrm{NaNO}_{2}$ was increased from 20 min to $60 \mathrm{~min}$, the fiber weight increased but there was no further fiber weight increase, and even a slight decrease, possibly because of diazo decomposition [3], when the reaction time was prolonged to $2.5 \mathrm{~h}$. Because such losses should be avoided, the reaction time between diethylenetriamine modified fiber and $\mathrm{NaNO}_{2}$ should not exceed $1 \mathrm{~h}$. After reaction and washing with cold water for short time the fiber must be immersed in ethanolic 8-hydroxyquinoline solution immediately to produce the red-brown 8-hydroxyquinoline-modified polyacrylonitrile fiber.

Fiber batch capacity test

A batch technique was chosen to determine which metal ions could be sorbed. By following the procedure described in the experimental section the capacity of $\mathrm{Ag}$, $\mathrm{Au}, \mathrm{Be}, \mathrm{Bi}, \mathrm{Co}, \mathrm{Cd}, \mathrm{Cr}(\mathrm{III}), \mathrm{Cu}, \mathrm{In}, \mathrm{Mn}, \mathrm{Ni}, \mathrm{Pb}, \mathrm{Pd}, \mathrm{Pt}$,

Table 2 Batch capacity $\left(\mu \mathrm{mol} \mathrm{g} \mathrm{g}^{-1}\right)$

\begin{tabular}{lllr}
\hline Element & $\begin{array}{l}\text { Batch } \\
\text { capacity }\end{array}$ & Element & $\begin{array}{c}\text { Batch } \\
\text { capacity }\end{array}$ \\
\hline $\mathrm{Ag}$ & 162.5 & $\mathrm{Au}$ & 111.9 \\
$\mathrm{Be}$ & 108.8 & $\mathrm{Bi}$ & 98.6 \\
$\mathrm{Co}$ & 212.5 & $\mathrm{Cd}$ & 208.3 \\
$\mathrm{Cr}(\mathrm{III})$ & 167.3 & $\mathrm{Cu}$ & 302.8 \\
$\mathrm{In}$ & 156.3 & $\mathrm{Mn}$ & 323.5 \\
$\mathrm{Ni}$ & 177.9 & $\mathrm{~Pb}$ & 138.5 \\
$\mathrm{Pd}$ & 105.7 & $\mathrm{Pt}$ & 98.6 \\
$\mathrm{Zn}$ & 315.6 & & \\
\hline
\end{tabular}

and $\mathrm{Zn}$ at $\mathrm{pH} 6$ was determined; the results are shown in Table 2.

\section{Breakthrough capacity}

The breakthrough capacity is affected by many factors, for example $\mathrm{pH}$, sample flow rate, etc. It is useful to evaluate how the effectiveness of the 8-hydroxyquinolinemodified polyacrylonitrile fiber is altered by changing one condition while holding the others constant. The breakthrough capacity demonstrates the suitability for preconcentration of trace metals. The effects of $\mathrm{pH}$, sample flow rate, alkali and alkaline earth cations on the breakthrough capacity and on fiber stability are discussed in detail below. The ratio of $\mathrm{Cu}(\mathrm{II})$ concentration in the eluate to that in initial solution $\left(\mathrm{C} / \mathrm{C}_{0}\right)$ was used as an indicator.

\section{Effect of pH on breakthrough capacity}

The effect of $\mathrm{pH}$ from 3 to 8 on $\mathrm{Cu}$ (II) breakthrough capacity was studied at a flow rate of $5 \mathrm{~mL} \mathrm{~min}^{-1}$ for a column packed with $100 \mathrm{mg}$ fiber (Fig. 4). It is apparent that the breakthrough capacity ( $95 \%$ of analytes adsorbed by the fiber) at $\mathrm{pH} 8$ was 29 mol, whereas at $\mathrm{pH} 3$ it decreased to $10 \mathrm{~mol}$, illustrating the competition of protons for exchange sites at low $\mathrm{pH}$. At $\mathrm{pH} 6$ the breakthrough capacity was $24.6 \mathrm{~mol}$; because the amount of fiber packed in the column was $100 \mathrm{mg}$ the capacity of the 8-hydroxyquinoline-modified polyacrylonitrile fiber for $\mathrm{Cu}(\mathrm{II})$ was $246 \mathrm{~mol} \mathrm{~g}^{-1}$ at this $\mathrm{pH}$. The profiles of these curves were not significantly different, indicating that film- and particle-diffusion control might be rate limiting under these experimental conditions.

\section{Effect of sample flow rate on breakthrough capacity}

Figure 5 shows the effect of flow rate on breakthrough capacity at $\mathrm{pH} 6$. It is apparent that increasing the flow rate

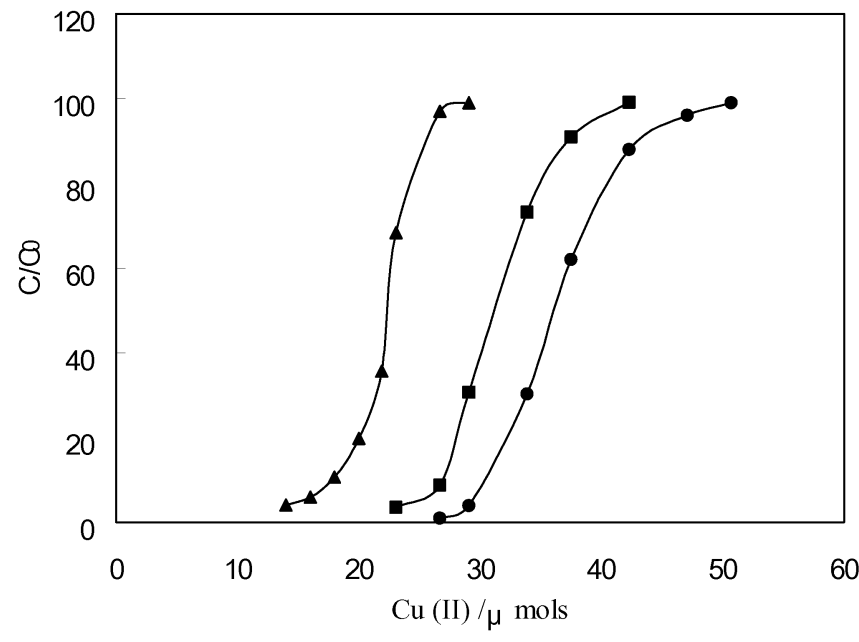

Fig. 4 Effect of $\mathrm{pH}$ on breakthrough capacity (circles, $\mathrm{pH} 8.0$; squares, $\mathrm{pH} 6.0$; triangles, $\mathrm{pH} 3.0$ ) 


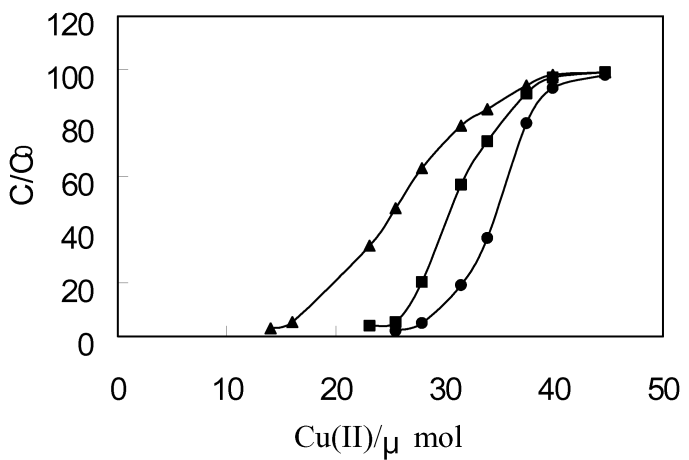

Fig. 5 Effect of sample flow rate on breakthrough capacity (cir-

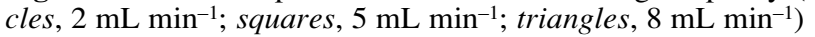

from 2 to $8 \mathrm{~mL} \mathrm{~min}^{-1}$ reduced the breakthrough capacity of $\mathrm{Cu}$ (II) from 278 to $200 \mathrm{~mol} \mathrm{~g}^{-1}$.

Although it is difficult to compare the breakthrough capacity directly with results from other workers, because of different experimental conditions such as column dimensions, $\mathrm{pH}$, sample flow rate, etc., some estimates can be made. Landing et al. [12] reported $294 \mathrm{~mol} \mathrm{~g}^{-1} \mathrm{Cu}$ (II) as the breakthrough capacity of 8-hydroxyquinoline-modified vinyl polymer agglomerate $\mathrm{pH} \mathrm{6.3,} \mathrm{sample} \mathrm{flow} \mathrm{rate}$ $0.2 \mathrm{~mL} \mathrm{~min}^{-1}$ ). Lofthouse et al. [22] reported a batch capacity value of $138 \mu \mathrm{mol} \mathrm{g}^{-1}$ and a dynamic capacity of $102 \mu \mathrm{mol} \mathrm{Mn}$ (II) $\mathrm{g}^{-1}$ for 8-hydroxyquinoline immobilized on a microporous silica frit. Compared with batch capacities reported in the literature for 8-hydroxyquinoline immobilized on other substances this value is greater than those reported by Marshall and Mottola [23], $185 \mu \mathrm{mol}$ $\mathrm{Cu}$ (II) $\mathrm{g}^{-1}$, Nelms et al. [24], $86 \mu \mathrm{mol} \mathrm{Cu}$ (II) $\mathrm{g}^{-1}$, Sturgeon [25], $61 \mu \mathrm{mol} \mathrm{Cu(II)} \mathrm{g}^{-1}$, Daihi [10], $10.4 \mu \mathrm{mol} \mathrm{Cu(II)} \mathrm{g}^{-1}$, and that of our previous product, $71.5 \mu \mathrm{mol} \mathrm{Cu}(\mathrm{II}) \mathrm{g}^{-1}$ [21]. Compared with those of other ion-chelating substances reported recently, the breakthrough capacity of our new material is equivalent to that of tiron-functionalized Amberlite XAD-2, $215 \mu \mathrm{mol} \mathrm{Cu}(\mathrm{II}) \mathrm{g}^{-1}$ [26], and greater than that of chromotropic acid-modified Amberlite XAD-2, $143.8 \mu \mathrm{mol} \mathrm{Cu}$ (II) $\mathrm{g}^{-1}$ [27], diethylenetriamine polymer, $80 \mu \mathrm{mol} \mathrm{Cu}$ (II) $\mathrm{g}^{-1}$ [28], and 1-(2-pyridylazo)-2- naphthol immobilized on alumina, $23.7 \mathrm{Cd}(\mathrm{II}) \mu \mathrm{mol} \mathrm{g}^{-1}$ [29].

\section{Effect of alkali and alkaline earth cations on breakthrough capacity}

To illustrate the possibility of concentrating trace metals from high salt matrices by use of immobilized 8-hydroxyquainoline the breakthrough capacity of $\mathrm{Cu}$ (II) was compared in the presence or absence of 20,000,500,2500, and $500 \mathrm{mg} \mathrm{L}^{-1}$ of $\mathrm{Na}^{+}, \mathrm{K}^{+}, \mathrm{Mg}^{2+}$, and $\mathrm{Ca}^{2+}$, respectively, as the chlorides. The results are shown in Fig. 6. In the presence of high concentrations of alkali and alkaline earth cations the breakthrough capacity of $\mathrm{Cu}(\mathrm{II})$ was reduced from 246 to $198.6 \mathrm{~mol} \mathrm{~g}^{-1}$. This breakthrough capacity was, nevertheless, still high enough for concentration of trace elements from real water samples. The 8-hydroxyquainolinemodified fiber could also effectively separate matrices.

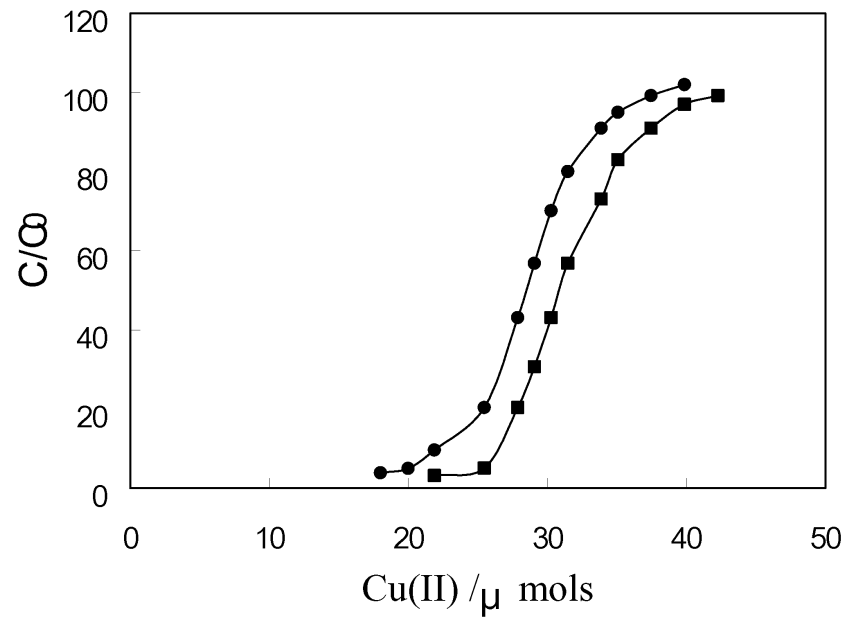

Fig. 6 Effect of alkali and alkaline earth elements on breakthrough capacity (circle, with matrix ions; squares, without matrix ions)

\section{Fiber stability}

Breakthrough capacity studies were also chosen for determination of the chemical stability of the modified fiber (pH 6.0, flow rate $5 \mathrm{~mL} \mathrm{~min}{ }^{-1}$ ). Copper(II) was used as the indicating species $\left(1 \mu \mathrm{g} \mathrm{mL}^{-1}\right)$. As shown in Fig. 7, after treatment with acid $\left(2 \mathrm{~mol} \mathrm{~L}^{-1} \mathrm{HCl}-0.1 \mathrm{~mol} \mathrm{~L}^{-1}\right.$ $\mathrm{HNO}_{3}$ ) for 2 and $48 \mathrm{~h}$, the breakthrough capacity was 24.4 and $24.2 \mathrm{~mol}$, respectively, indicating that the fiber was very stable in acidic solution.

Similarly, soaking in $0.5 \mathrm{~mol} \mathrm{~L}^{-1} \mathrm{NaOH}$ for $2 \mathrm{~h}$ had little effect on the breakthrough capacity (Fig. 8). After treatment for $48 \mathrm{~h}$, despite obvious reddish coloration of the basic solution, indicating base-catalyzed hydrolysis, the breakthrough capacity increased to $33.6 \mathrm{~mol}$, possibly because of the formation of carboxyl groups [18].

\section{Blank and detection limits}

Blank values for analyte determinations were obtained by performing the preconcentration procedure using $500 \mathrm{~mL}$

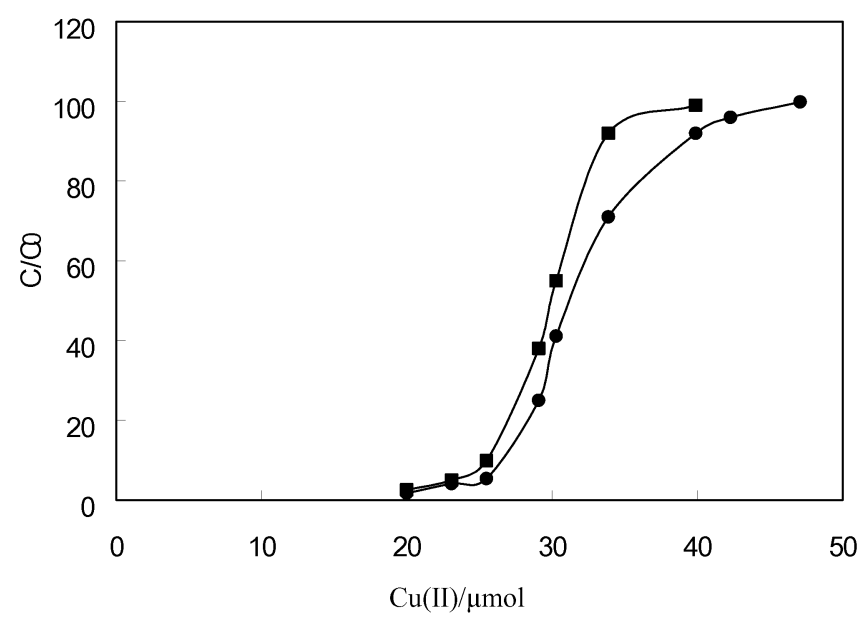

Fig. 7 Effect of acid treatment on breakthrough capacity (circles, 2-h acid treatment; squares, 48 -h acid treatment) 


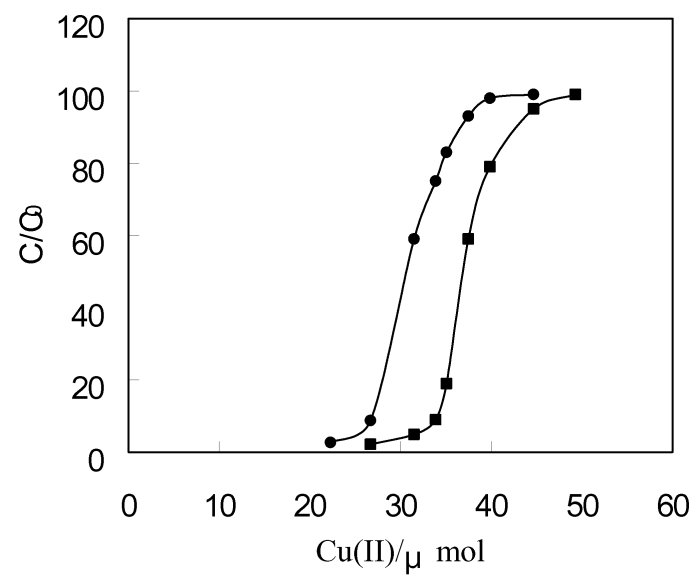

Fig. 8 Effect of treatment with alkali on breakthrough capacity (circles, 2-h alkali treatment; squares, 48-h alkali treatment)

Table 3 Blanks and detection limits (ng L $\left.{ }^{-1}\right)$

\begin{tabular}{|c|c|c|c|c|}
\hline \multirow{2}{*}{$\begin{array}{l}\text { Ele- } \\
\text { ment }\end{array}$} & \multicolumn{2}{|l|}{ Blank } & \multicolumn{2}{|c|}{ Detection limit } \\
\hline & $\begin{array}{l}\text { One blank } \\
\text { solution }\end{array}$ & $\begin{array}{l}\text { Eleven blank } \\
\text { solutions }\end{array}$ & $\begin{array}{l}\text { One blank } \\
\text { solution }\end{array}$ & $\begin{array}{l}\text { Eleven blank } \\
\text { solutions }\end{array}$ \\
\hline $\mathrm{Ag}$ & 9.4 & 10.8 & 5.6 & 5.8 \\
\hline $\mathrm{Be}$ & 17.1 & 31.4 & 51.6 & 52.5 \\
\hline $\mathrm{Cd}$ & 4.1 & 6.4 & 6.1 & 6.4 \\
\hline $\mathrm{Co}$ & 2.9 & 3.0 & 0.4 & 1.0 \\
\hline $\mathrm{Cu}$ & 4.8 & 9.3 & 9.8 & 11.6 \\
\hline $\mathrm{Ni}$ & 310.0 & 319.7 & 27.3 & 29.8 \\
\hline $\mathrm{Mn}$ & 22.9 & 76.0 & 121.5 & 129.1 \\
\hline $\mathrm{Pb}$ & 41 & 48.8 & 12.6 & 13.6 \\
\hline $\mathrm{Zn}$ & 101.2 & 129.8 & 88.7 & 89.3 \\
\hline
\end{tabular}

doubly-distilled deionized water as a sample and $5 \mathrm{~mL}$ $2 \mathrm{~mol} \mathrm{~L}^{-1} \mathrm{HCl}-0.1 \mathrm{~mol} \mathrm{~L}^{-1} \mathrm{HNO}_{3}$ as eluent. The detection limits for the method were calculated on the basis of three times the standard deviation of 11 runs of one blank solution or that from one run of 11 blank solutions. The detection limits and blank values are shown in Table 3. It is clearly apparent that the blank and detection limit values of two approaches were similar in magnitude. Compared with the concentrations of analytes present in seawater and river water samples (Table 4) all analyte concentrations in the real samples are much greater than the detection limits after 100 -fold preconcentration.

Determination of trace metals in water samples

From the breakthrough and batch capacity studies it is apparent that the 8-hydroxyquinoline-modified polyacrylonitrile fiber has a relative high capacity for many metal ions, and its kinetic characteristics are satisfactory. The newly 8-hydroxyquinoline-modifed polyacrylonitrile fiber was applied to the determination of trace metals in certified reference materials NASS-5, CASS-3, CASS-5 seawater, and SLRS-4 river water. The results shown in Table 4
Table 4 Determination of trace metals in the certified seawater (CASS-4, NASS-5, and SLEW-3) and river water(SLRS-4) samples $\left(\mu \mathrm{g} \mathrm{L}^{-1}\right)^{\mathrm{a}}$

\begin{tabular}{llllll}
\hline \multirow{2}{*}{$\begin{array}{l}\text { Ele- } \\
\text { ment }\end{array}$} & CASS-4 & & & NASS-5 & \\
\cline { 2 - 3 } \cline { 5 - 6 } & Measured & Certified & & Measured & Certified \\
\hline $\mathrm{Cd}$ & $0.029 \pm 0.002$ & $0.026 \pm 0.003$ & & $0.021 \pm 0.002$ & $0.023 \pm 0.003$ \\
$\mathrm{Co}$ & $0.026 \pm 0.002$ & $0.026 \pm 0.003$ & & $0.010 \pm 0.001$ & $0.011 \pm 0.003$ \\
$\mathrm{Cu}$ & $0.638 \pm 0.038$ & $0.592 \pm 0.055$ & & $0.269 \pm 0.023$ & $0.297 \pm 0.046$ \\
$\mathrm{Ni}$ & $0.324 \pm 0.020$ & $0.314 \pm 0.030$ & & $0.218 \pm 0.020$ & $0.253 \pm 0.028$ \\
$\mathrm{Mn}$ & $2.75 \pm 0.021$ & $2.78 \pm 0.19$ & & $0.962 \pm 0.046$ & $0.919 \pm 0.057$ \\
$\mathrm{~Pb}$ & $0.105 \pm 0.0012$ & $0.0098 \pm 0.0036$ & $0.010 \pm 0.001$ & $0.008 \pm 0.005$ \\
$\mathrm{Zn}$ & $0.372 \pm 0.030$ & $0.381 \pm 0.057$ & $0.099 \pm 0.010$ & $0.102 \pm 0.039$ \\
\hline & $\mathrm{SLEW}-3$ & & & & \\
& & & & & \\
\hline $\mathrm{Ag}$ & $0.003 \pm 0.0003$ & $(0.003)^{\mathrm{a}}$ & & & \\
$\mathrm{Be}$ & - & - & $0.006 \pm 0.0005$ & $0.007 \pm 0.002$ \\
$\mathrm{Cd}$ & $0.050 \pm 0.003$ & $0.048 \pm 0.004$ & $0.14 \pm 0.01$ & $0.12 \pm 0.002$ \\
$\mathrm{Co}$ & $0.043 \pm 0.002$ & $0.042 \pm 0.010$ & $0.035 \pm 0.003$ & $0.033 \pm 0.006$ \\
$\mathrm{Cu}$ & $1.49 \pm 0.13$ & $1.55 \pm 0.12$ & & $1.87 \pm 0.09$ & $1.81 \pm 0.08$ \\
$\mathrm{Ni}$ & $1.26 \pm 0.06$ & $1.23 \pm 0.07$ & $0.63 \pm 0.05$ & $0.67 \pm 0.08$ \\
$\mathrm{Mn}$ & $1.60 \pm 0.13$ & $1.61 \pm 0.22$ & $3.20 \pm 0.11$ & $3.37 \pm 0.18$ \\
$\mathrm{~Pb}$ & $0.0087 \pm 0.0007$ & $0.0090 \pm 0.0014$ & $0.086 \pm 0.003$ & $0.086 \pm 0.007$ \\
$\mathrm{Zn}$ & $0.210 \pm 0.020$ & $0.201 \pm 0.037$ & $0.98 \pm 0.07$ & $0.93 \pm 0.10$ \\
\hline
\end{tabular}

aThree measurements

are mean values \pm standard deviations. There is a good agreement between the data obtained by the recommended method and the certified values.

\section{Conclusion}

In the work discussed in this report a rapid synthetic route has been devised for effective immobilization of 8-hydroxyquinoline on the polyacrylonitrile fiber. Compared with other immobilized materials this product has the following features:

1. ease of synthesis;

2. the breakthrough and batch capacity of this fiber are greater than for most of other 8-hydroxyquinolinemodified materials reported in the literature;

3. stability in acidic or alkaline conditions is satisfactory; and

4. the mechanical strength is higher and the material can be stored and applied conveniently.

The effectiveness of the concentration of multi-trace metals from complicated matrices was verified and the results confirmed that the modified fiber is suitable for determination of trace metals in certified seawater and river water samples, indicating the modified fiber has good prospects.

Acknowledgements This study was supported by the Chinese Academy of Sciences (KZCX2-410), the Basic Research Development Programme (G1999045710) and Hi-tech Research and Development Program of China (2000AA635050). 


\section{References}

1. Jarvis KE, Gray AL, Houk RS (1992) (eds) Handbook of inductively coupled plasma mass spectrometry. Blackie

2.Zhang TH, Shan XQ, Liu RX, Tang HX (1998) Anal Chem 70:3964-3968

3. Esser BK, Volpe A, Kenneally JM, Smith DK (1994) Anal Chem 66:1736-1742

4. Nickson RA, Hill SJ, Worsfold PJ (1995) Anal Proc 32:387395

5. Beceiron-Gonzalez E, Barciela-Garcia J, Bermejo-Barrera P, Bermejo- Barrera A (1992) Fresenius J Anal Chem 344:301305

6. Beauchemin D, Berman SS (1989) Anal Chem 61:1857-1862

7. Halicy L, Gavrieli I, Dorfman E (1996) J Anal At Spectrom 11: 811-814

8. Willie SN, Sturgeon RE, Berman SS (1983) Anal Chim Acta 49:59-66

9. Leyden DE, Luttrell GH, Sloan AE, DeAngells NJ (1976) Anal Chim Acta 84:97-108

10. Daih B, Huang H (1992) Anal Chim Acta 258:245-252

11. Resing JA, Mottl MJ (1992) Anal Chem 64:2682-2687

12. Landing WM, Haraldsson C, Paxeus N (1986) Anal Chem 58: 3031-3035

13. Halicz L, Gavrieli I, Dorfman E (1999) J Anal At Spectrom 14: $1839-1842$
14. Orians KJ, Boyle EA (1993) Anal Chim Acta 282:63-74

15. Vicente O, Padro A, Martinez L, Olsina R, Marchevsky E (1998) Spectrochim Acta B 53:1281-1287

16. Hill JM (1973) J Chromatogr 76:455-458

17. Fulcher C, Crowell MA, Bayliss R, Holl KB, Jezorek JR (1981) Anal Chim Acta 129:29-47

18. Zhang BW, Fischer K, Bieniek D, Kettrup A (1994) React Polym 24:49-58

19. Wen B, Shan XQ, Liu RX, Tong HX (1999) Fresenius J Anal Chem 363:251-255

20. Wen B, Shan XQ, Xu SG (1999) Analyst 124:621-626

21. Wen B, Shan XQ, Xu SG (2000) Int J Environ Anal Chem 77:95-109

22. Lofthouse SD, Greenway GM, Stephen SC (1999) J Anal At Spectrom 14:1839-1842

23. Marshall MA, Mottola HA (1985) Anal Chem 57:729-733

24. Nelms SM, Greenway GM, Hutton RC (1995) J Anal At Spectrom 10:929-933

25. Sturgeon ME, Berman SS, Willie SN, Desaulniers JAH (1981) Anal Chem 53:2337-2340

26. Kumar M, Rathore DPS, Singh AK (2000) Analyst 125:12211226

27. Kumar PT, Singh AK (1999) Analyst 124:1847-1851

28. Bakircioglu Y, Seren G, Akman S (2001) Anal Lett 34:439_ 447

29. Shemirani F, Akhavi BS (2001) Anal Lett 34:2179-2188 